\title{
SCXTREME Framework: A Customized Approach of Process Improvements in Agile Blend with CMMI Practices in Pakistan
}

\author{
Samina Jan \\ University of Engineering \& Technology, Taxila, Pakistan \\ Email:ifsami@gmail.com \\ Ali Javed \\ University of Engineering \& Technology, Taxila, Pakistan \\ Email: ali.javed@uettaxila.edu.pk
}

\begin{abstract}
The proposed framework shows the customized approach that improves the software development process by using the Agile techniques. The proposed research work blends the CMMI practices according to Agile methods of development (specially Scrum, because Scrum is extremely used by Pakistani firms)
\end{abstract}

CMMI is a model for the process improvement within organization, but it is too expensive to implement all practices of CMMI for each level. So for small size organizations, at level 2, 3 there are some practices which are helpful in managing and defining their software development process. By implementing the proposed framework, organizations can improve their maturity and capability level.

There are several problems while working on Agile, many management areas can be neglected. In SCXTREME there are eight process area selected from CMMI and fit them according to Agile, so agile can be suitable for Pakistani organization by implementing some process area at level 2 and level 3.

Index Terms - CMMI, Agile, Scrum,XP, Pakistan

\section{Introduction}

Software development can be performed by different models like typical waterfall, Spiral, Incremental, Rational Unified, RAD etc. Before Agile techniques, waterfall model was considering the best one. Software engineering evolves with the passage of time; experts realized the nature of software engineering which is volatile and instable because of acceptance of changes during the products development process.

Following are the short descriptions of basic terms which will use in research work:

\subsection{Agile Methodology}

Agile software development focuses on the individuals (the customers) and their interaction with agile teams, Agile tries to give desired working products and accept the change from customer.

\subsection{Different Agile Methods}

Different agile methods are:

$\rightarrow$ Dynamic Systems Dev Method(DSDM)

$\rightarrow$ Crystal Clear

$\rightarrow$ Extreme Programming (XP)

$\rightarrow$ Scrum

$\rightarrow$ Adaptive Software Development (ASD)

$\rightarrow$ Feature Driven Development (FDD)

Main agile methods which are frequently used in Pakistan are the Scrum, Feature Driven and Extreme Programming (XP). The graph shows the \% of usage Agile[1].

\section{Agile in Pakistan}

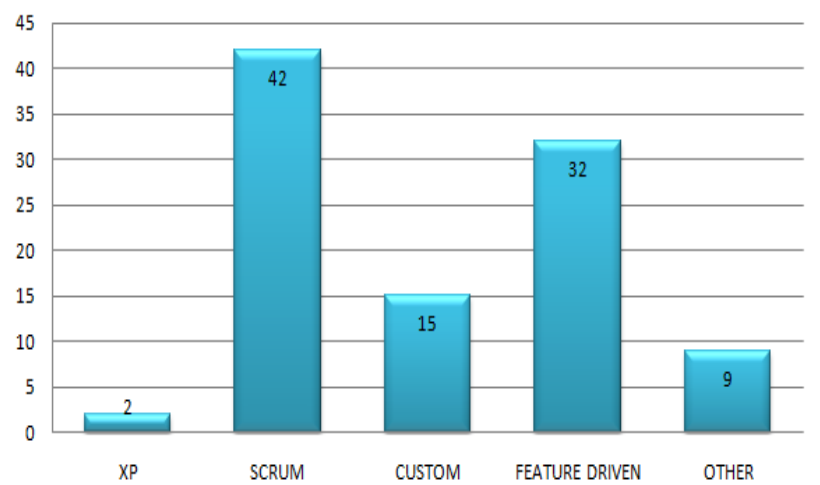

Fig. 1: Agile in Pakistan 


\subsection{CMMI}

The SEI (software engineering institute) has defined the CMM that represent the principle of process management stated that product quality is based on process quality which is used for the development of product.

\subsection{Levels of CMMI}

The main focus of research is on level 2 and on level 3. These are the initial levels for process improvement in the organizations.

The proposed research paper is organized in six sections, Section 1 is Introduction includes main concept of Agile and CMMI is described. In the Section 2 literature review is presented, where review on different models for the software development has been mentioned. Section 3 explains the reason why it is needed to propose a new framework for the Pakistan software industry. Section 4 is proposed framework section, which has been analyzed on the basis of existing agile methodologies and CMMI model. Finally the proposed work is concluded in Section 5.

\section{Literature Review}

Different models and framework exist now-a-days for process improvement. Rajiv Kishore et al. [2] developed quality distinction (QD) model which measures four (one dynamic capability and three operational) capabilities. Capabilities are build on the base of CMM integration framework. In the model there are 2 stages and in 1st stage there are 2 rounds.

Stage 1: In 1st Round assign the CMMI Processes area to QD Capability Model using Expert Judgment method, experts assigned each CMMI process to a capability defined in QD capability model. In 2nd round, delphi and sorting approaches used.

Stage 2: Hypothesis testing through model comparison survey is conducted, for analysis purpose fivepoint Likert scale approach is used.

So they proved that QD capability model can provide improved capabilities in the field of IT with the use of CMMI.

Lina Zhang et al. [3] proposed approach for small and medium size organizations. According to them project development process is divided into software iterative processes and project management. Companies can improve their Software process by having less resources and implementing Software iterative processes Incremental delivery and Spiral development methods.

Tsvetelina Kovacheva et al. [4] belong to Musala Soft (Bulgaria). They selected the Trac model as an optimized solution for software development process. It is an integrated Agile-CMMI process model and open source software which provides documents, source code and project tracking. Yi-Ling Kuo et al. [5] proposed an E-Learning system which is based on CMMI. They proposed the new learning approach by enhancing the spiral capability. Model enables a student to review about him/her self and know about his/her learning capability and also can get the feedback from the system and on the basis of feedback, he can enhance his capabilities. Simultaneously, teacher can check the student's learning capability and update their way of teaching accordingly.

M. Nawazish Khokhar [6] et al. suggest MECA model. Model is continuous which consist of 4 stages MECA stands for Monitor, Evaluate, Control and Act.

$\rightarrow$ Monitor Phase: keep track of all activities performed in project development process.

$\rightarrow$ Evaluate Phase: evaluation of the project will perform against the pre-defined organization policies or standards.

$\rightarrow$ Control Phase: plan some actions against the abnormalities exist in the project to control it.

$\rightarrow$ Act Phase: actions will perform which were defined in Control phase to correct the faults.

Viljan Mahnic [7] implemented an undergraduate capstone course in software engineering. In the course, students get the experience on agile methodologies; also observe the behavior of developers using Scrum for the first time. The course requires students to work as Scrum Teams, which implements the user stories and project experts will perform the role of product owner. Data from project management activities are collected to analyze that how much work is completed, how much remaining and estimating the effort applied on work and effort need to apply. At the end, summary of lesson learned is given.. Vladan .D at el. [8] researched on Agile in the field of teaching. Teaching in agile way in effective if agile manifesto applies in such a manner:

$\rightarrow$ Value the agile students "over" book process

$\rightarrow$ Value the students' skills which built through practice "over" complete understanding about strange things.

The teacher's role should represent the principle of "guide on the side, not a sage on the stage".

Hisham M. Haddad et al. [9] suggest a practical approach for instituting small level software organizations. They proposed a simple framework to realize a metrics program which is based on the Goal/Question/Metric (GQM) paradigm.

GQM approach defines the goals an organization wishes to achieve, now each goal will divide into one or more than one questions, against each question there is 
one or more metrics (which consist of required data). A successful implementation of any framework requires the long-term commitment of the technical and manage ment staff to ensure success. Muhammad Ishfaq et al.[10] analyzed the Pakistan software industry and they proposed that Pakistani software industry should implement the Agile software development methodology. In Pakistan, software industry is not at its peak, so direct adoption of CMMI is not suggested for firms, CMMI is expensive so small size organizations can move towards Agile. Many Agile methodologies can fit with the CMMI for better performance. They use Extreme Programming (XP), and map XP with the CMMI.

ZUXiao-Fang [11] et al. concluded some problems exist in CMMI. They mentioned in their proposed work that CMM only considers the impact of software process, but not satisfactory for non-process factors for software development. The skills and experience of project participants, the developing technologies and tools used, the type and complexity of software products, as well as the overall environ ment of software development are the non-process factors. H. Malik [12] et al. analyzed the existing problems in agile development. Their research depicts that the agile methodologies are not suitable for maintenance. Communication with the customer is the key of success. But unfortunately it is assumed that the quality of product depends on the developer's skills and his behavior, while the main design of product mostly done by single developer. If any existing system is required to reuse, in this case agile is not suitable. Abdul Rauf [13] at el. discussed in their research work that Pakistan software industry is implementing CMMI practice but still facing some challenges:

$\rightarrow \quad$ It is difficult for the organizations to gain the clients from foreign market and if clients come, they can't understand client's project domain.

$\rightarrow \quad$ Understand the existing local market

$\rightarrow$ Pakistani products/service level up by hiring the experienced quality persons

$\rightarrow \quad$ Small size organization s

$\rightarrow$ Top level management unable to understand how to improve the processes

$\rightarrow$ Lack of long term objectives in business

\section{Why Need for New Framework?}

Due to instability in the requirements, software engineering is facing three major problems: poor quality, late delivery and overrun budget. The Software Engineering Institute (SEI) created the CMMI for the organizations that verifies the quality of product. Now the question is that why new approach is needed? In
Agile some issues exist, due to which it is not absolutely suitable for Pakistani software industry:

- Maintenance of documentation

- Change Control and different practices comes under CMMI that can be essential for agile methodologies are neglecting.

- Due to lack of good Process implementation, late delivery of project and budget overrun problems are faced by the organizations.

Research work proposed a process improvement framework which will improve organizational work, Improvement in Work will ensure that the developed products are reliable and meeting the customers' expectations. Although many results from Pakistan software industry showed that organizations avoid to implement CMMI because it requires a large amount of budget and time, while on the other side, customer wants the product as soon as possible and according to their requirements. Organizations avoid Agile development approach because it requires highly experienced developers who could easily built application according to the customer needs and accept changes whenevercustomer requirements changes.

\section{Proposed Framework}

The proposed framework SCXTREME is the combination of both Agile and CMMI. Agile have several methods, but the research work will focus on Scrum and Extreme Programming. Pakistan software industry is either following the CMMI process areas or agile methods. But research work shows the combination of both Methods. It is because in both methods there are some issues, research try to overcome these is sues exist in CMMI and Agile.

For research purpose, following are the selected process area for the SCXTREME framework:

$$
\begin{aligned}
& \rightarrow \text { Project Planning (PP) (Level 2) } \\
& \rightarrow \text { Configuration Management (CM) (Level 2) } \\
& \rightarrow \quad \text { Risk Management (RSKM) (Level 3) } \\
& \rightarrow \quad \text { Requirements Management (REQM) (Level 2) } \\
& \rightarrow \quad \text { Process and Product Quality Assurance (PPQA) } \\
& \quad \text { (Level 2) } \\
& \rightarrow \quad \text { Verification (VER) (Level 3) } \\
& \rightarrow \text { Measurement and Analysis (MA) (Level 2) } \\
& \quad \text { Project Monitoring and Control (PMC) (Level 2) }
\end{aligned}
$$

There are 22 Process Areas in CMMI, but for the research purpose eight process areas are selected which are on the CMMI level 2 and level 3 for the small size software organizations in Pakistan. They can implement 
easily within their resource and budget constraints. Frame work elaborates each specific goal which comes in a process area, it elaborate specific practices which come under specific goal. Following are the process areas defined in SCXTREME Framework:

\section{SCXTREME Framework}

\subsection{Requirements Management}

While performing requirements management activity, there is a specific goal ( $\mathrm{SG}$ ) named manage requirements and against the $\mathrm{SG}$, there are four specific practices (SPs) like obtain an understanding of Requirements, Obtain Commitment to Requirements, Manage Requirements Changes, and Maintain Bidirectional Traceability of Requirements.

Now against each CMMI Specific practice there are some sets of agile practices and the proposed SCXTREME Practices in which there is a combination of both CMMI practice and can imp lement on firms that follow agile development approach specially Scrum.

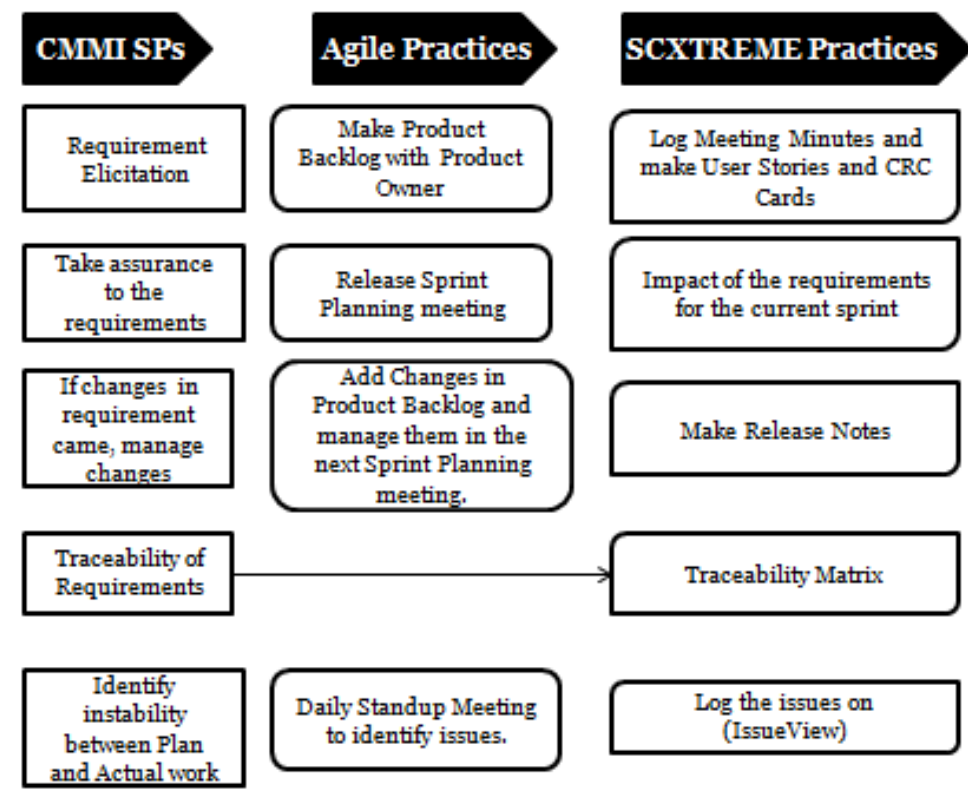

Fig. 2: Manage Requirements

\subsection{Project Planning}

In project planning, there are three specific Goals (SGs): establish estimates, develop project plan and commitment on plan.

\subsubsection{Establish Estimates}

Under this SG, there are four specific practices.

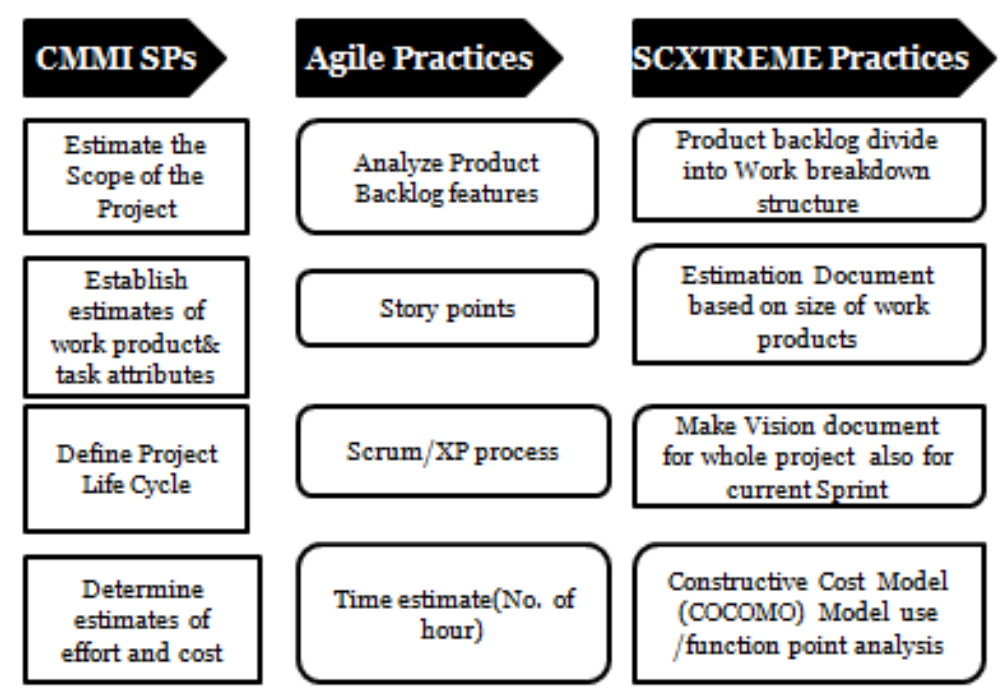

Fig. 3: Establish Estimates 
In given approach against each SP, there exist agile practice, SCXTREME proposed practices with some change, scope estimation should be accomplished by consulting with the product owner, SCXTREME approach also ensures to create a work break down
(WBS) structure. Some documents proposed by the framework which are neglected by the Agile Methods.

\subsubsection{Develop Project Plan}

Under this SG, there are seven specific practices.

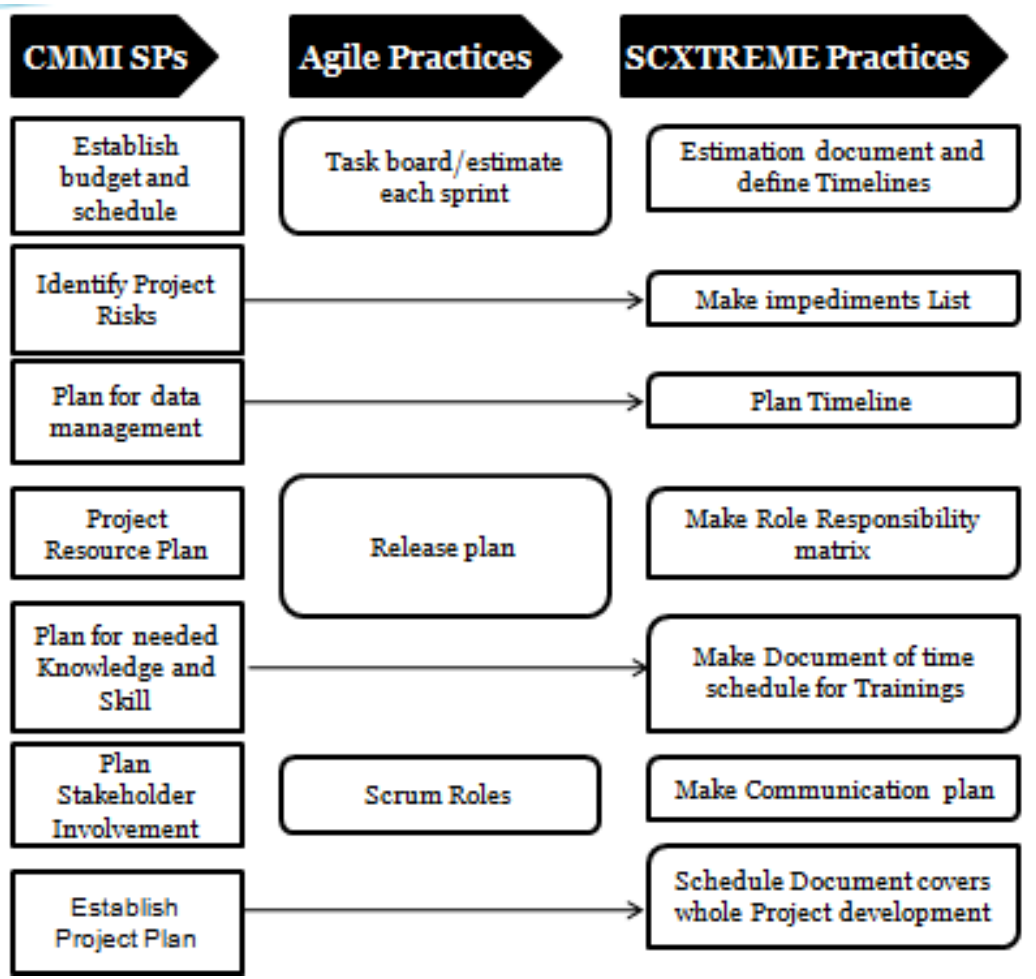

Fig 4: Develop Project Plan

Timeline document is suggested for the schedule of the project, in which start, end time, resources, time and effort variance is defined. Project list will be defined in impediments list and further the list will be evaluated in sprint review meeting, in which analysis will be performed on impediments came while developing the sprint.

\subsubsection{Commitment on Plan}

Under this SG, there are three specific practices.

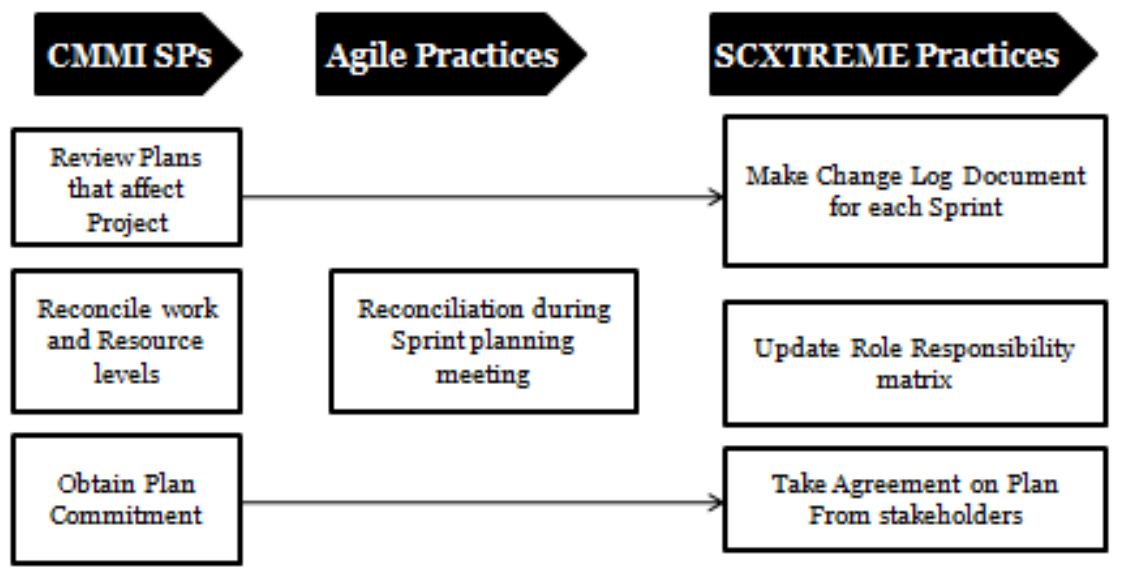

Fig. 5: Commitment to Plan

Prepare change log document which will specify the changes occur at each review of plan. Plan build up for the current sprint, so the agreement from customer on the sprint tasks can be conducted. 


\subsection{Configuration Management}

Software configuration management consists of following areas:

$$
\begin{aligned}
& \rightarrow \text { Version control } \\
& \rightarrow \text { Change management } \\
& \rightarrow \text { Document control } \\
& \rightarrow \text { Release control. } \\
& \rightarrow \text { Build management }
\end{aligned}
$$

It is the major area which is usually neglected by the Agile approach. Initial Product backlog is considered as baseline for the project. So whenever change comes in product backlog it is updated accordingly.

\subsubsection{Establish Baselines}

Under this SG, there are three specific practices. Baseline is the document on which further progress is dependent. First identify the CIs (configuration items), in agile CI Sheet will make on the base of product backlog items. Select the system as a tool to maintain changes. Make a directory in tool named baseline and create a baseline document and store in it.

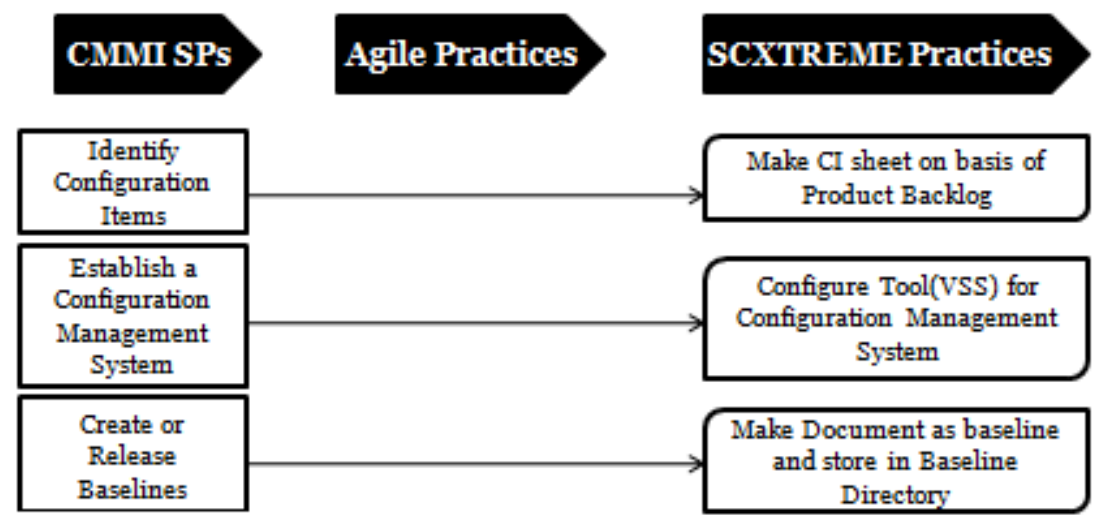

Fig. 6: Establish Baselines

\subsubsection{Track and Control Changes}

To keep track of changes, first make a change request document and also analyze the impact of change on the project. When the change implements, the baseline will update and the concern CIs also, so maintain the revision history of updated documents for each sprint.

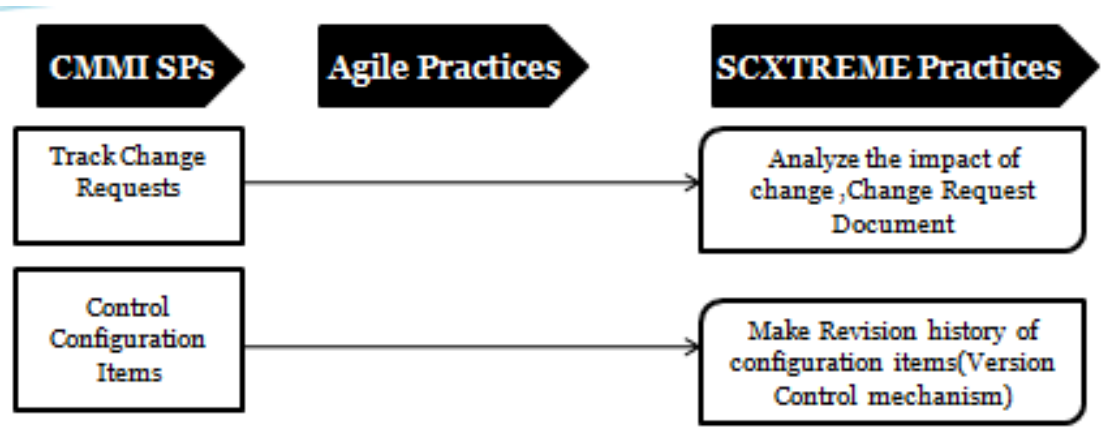

Fig. 7: Track and control changes

\subsubsection{Establish Integrity}

It is needed to maintain the revision history of baseline and change log document updated. A configuration audit verifies that the baselines and documentation are according to the standard (template, standard that organization follows).

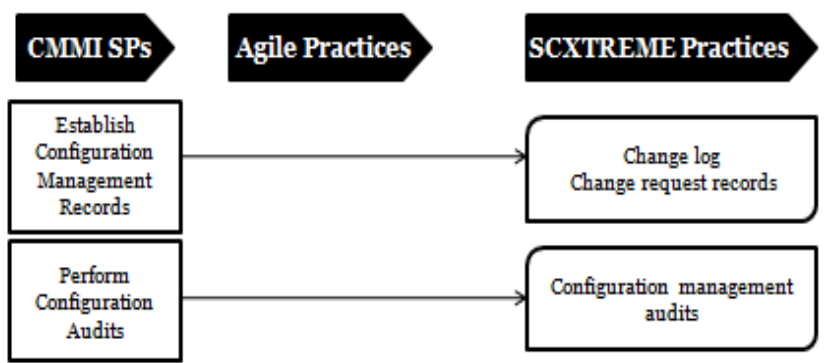

Fig. 8: Establish Integrity 


\subsection{Risk Management}

Risk management is to identify the possible problem before they occur.

\subsubsection{Prepare for Risk Management}

First identify the risk categories in daily stand up/ scum meetings. Risk has different levels. List down different parameters of risk with their likelihood, and establish risk management strategy like risk mitigation techniques and maintain burndown charts.

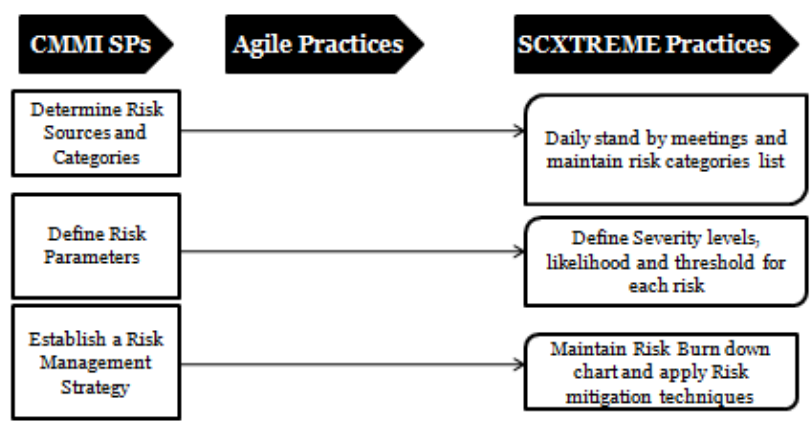

Fig. 9: Prepare for Risk Management

\subsubsection{Identify and Analyze the Risks}

In agile it is easy to identify the risk by conducting daily scrum meetings.

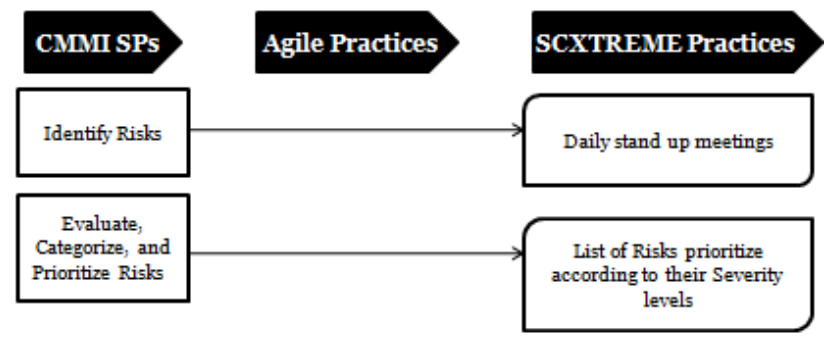

Fig. 10: Identify and Analyze the Risks

\subsubsection{Mitigate Risk}

It is a good practice to maintain contingency plan to handle the risks. Make a document which includes the actions taken against the risk.

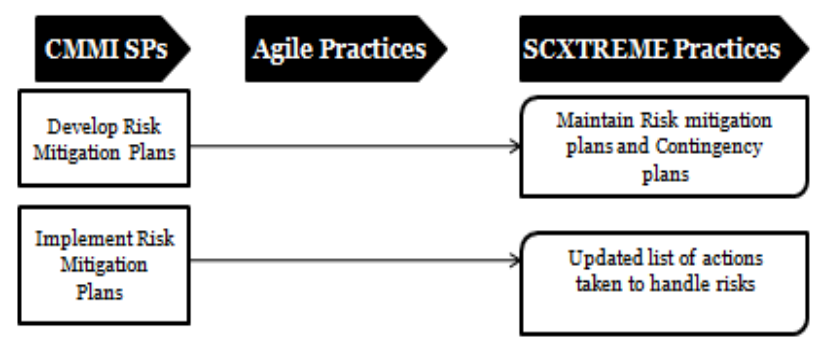

Fig. 11: Mitigate Risk

\subsection{Process and Product Quality Assurance}

It ensures that product implements the desired level of quality; it also involves the visibility of the staff and mangers also.

\subsubsection{Objectively Evaluate Processes and Work Products}

Evaluate the process followed and Sprint evaluations at sprint review meeting with product owner, scrum master and team members.

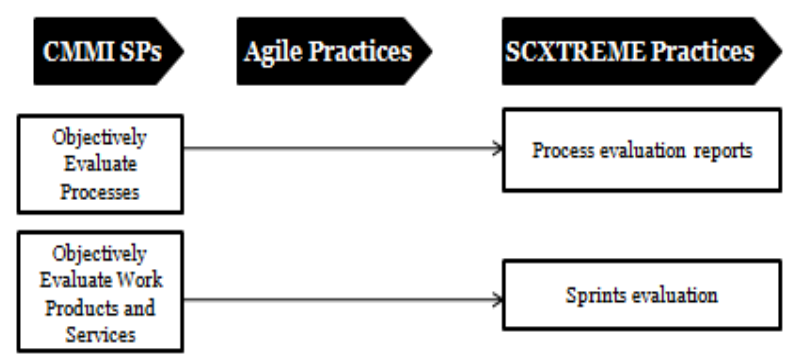

Fig. 12: Objectively Evaluate Processes and Work Products

\subsubsection{Provide Objective Insight}

The problem identified in evaluations are said to be non-compliance issues these are because of failure to act according to standards given followed by the organization. So communicate these issues with the team and maintain the QA reports that list down issues and solutions applied.

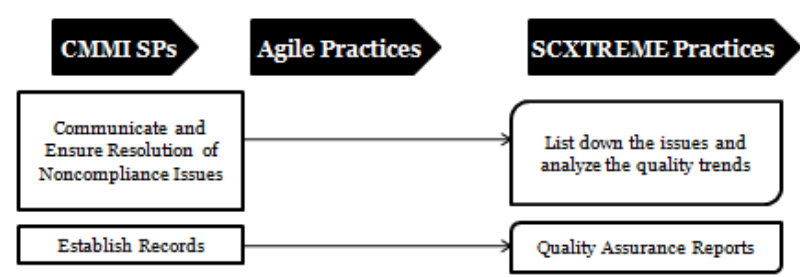

Fig. 13: Provide Objective insight

\subsection{Verification (VER)}

Verification providing that end product//module should develop according to requirement specified.

\subsubsection{Prepare for Verification}

Select the artifacts/work product which is required for the verification. Current sprint is the work product for verification, try to establish the verification environment choose the way of verification walkthrough, peer reviews etc, in case of agile while team are small in size peer review and sprint review meetings are the approaches for verification. And criteria of verification vary from organization to origination. 


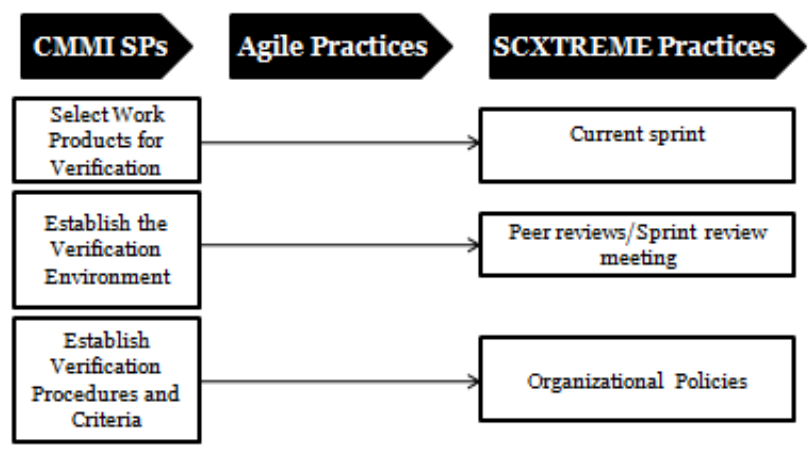

Fig. 14: Prepare for Verification

\subsubsection{Perform Peer Reviews}

Prepare a checklist of current sprint tasks, in sprint review meeting, discuss tasks and analyze the impact of defect on the current sprint and try to overcome them.

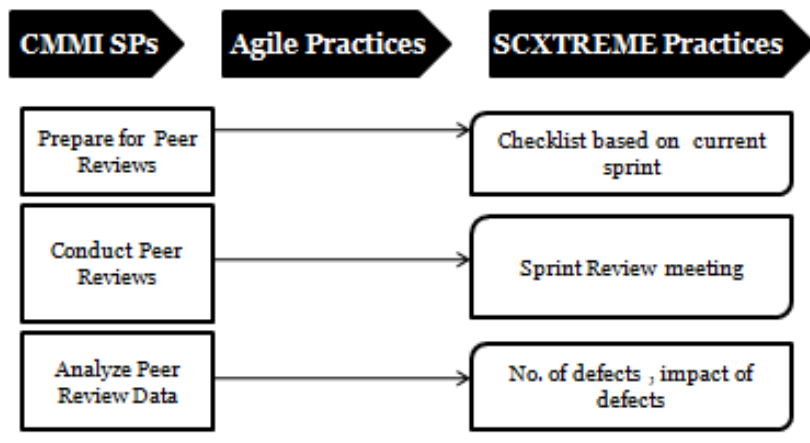

Fig. 15: Perform Peer Reviews

\subsubsection{Verify Selected Work Products}

In Agile Scrum verification can be performed by project task board which tells how much work is done. All these artifacts of sprint are required to discuss in sprint review meeting in front of product owner, and scrum master and they actually verify the sprint.

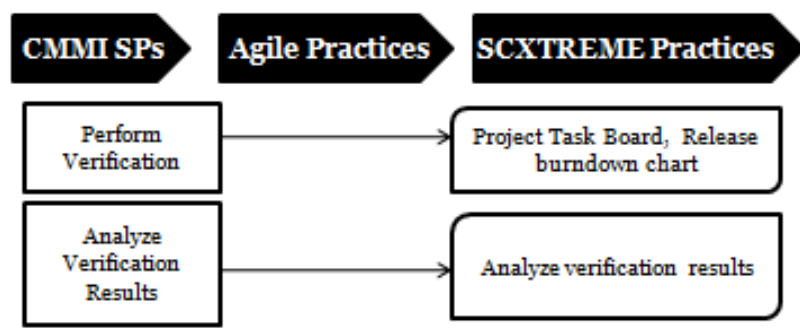

Fig. 16: Verify Selected work products

\subsection{Measurement and Analysis}

It is about to develop the measurement capability which is used to support the management activities.

\subsubsection{Align Measurement and Analysis Activities}

At the time of planning the measurement criteria, constraints on the measurements, tradeoff should be kept in mind.

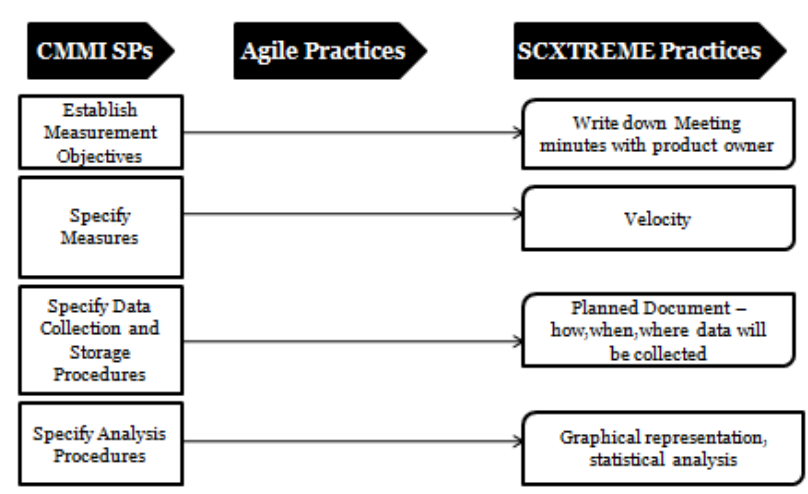

Fig. 17: Align Measurement and Analysis Activities

Establish measurement objectives include reduce product deployment time, reduce the lifecycle cost etc. so solution is that write down the meeting minutes and implement the required requirements which were discussed in meeting to adjust the time, budget sort of constraints. Already Specified measures are defined by Velocity. Velocity in scrum is a tool that is used to measure the team consistency deliver business value at a specific rate. For other SPs planned document and graphical representations are required.

\subsubsection{Provide Measurement Results}

Communication with the product owner and meeting with the team members on the result is required. Retrospective in which all progress discuss with team members and discus draft document with product owner for verifying the measured data.

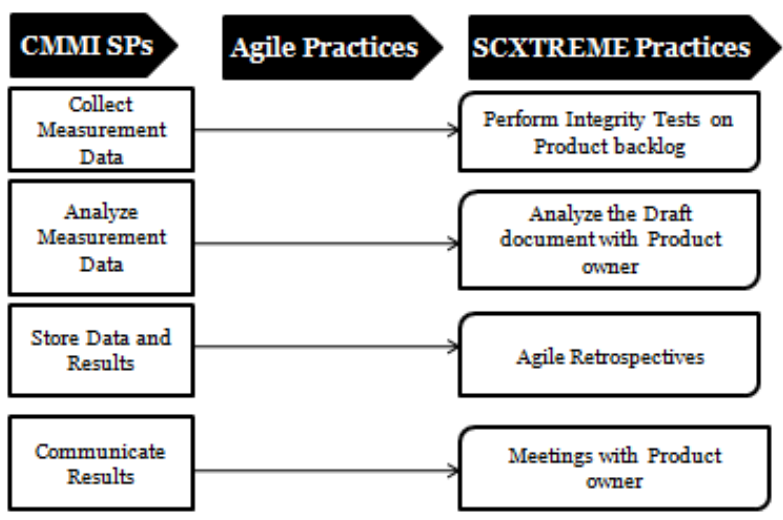

Fig. 18: Provide measurement results

\subsection{Project Monitoring and Control}

Project monitoring and control process area monitor the project progress. Project monitoring and control process area consist of two specific goals. 


\subsubsection{Monitor Project against Plan}

In agile there are many ways to monitor the progress of the project like daily scrum meetings, sprint burndown chart, task board. Whenever progress of project is concerned, task board is a best choice for small size organizations. Project task board keeps track of user stories which cover the whole project. Monitor the commitments project plan that should be listed in daily meetings. Project risks that are managed in sprint planning meeting will highlight the risks. Monitoring of data management discuss in retrospective meeting. CMMI milestone of project means each sprint in Scrum.

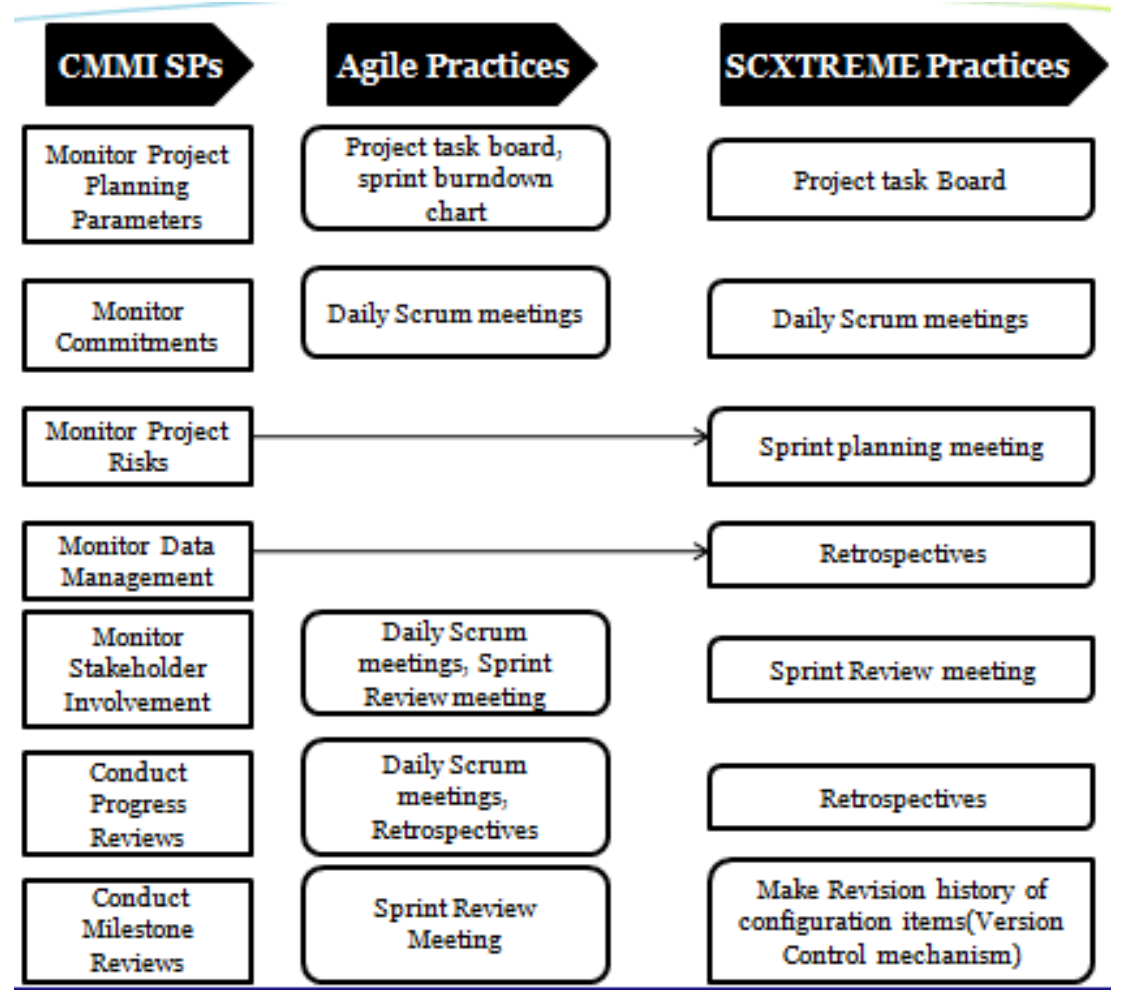

Fig. 19: Monitor Project against Plan

\subsubsection{Manage Corrective Action to Closure}

Some approved actions are required to finish the project. It is possible that there exist many issues in the project, analyzes the issues in daily stand up/ scrum meetings. And if issues come, take corrective actions and manage them in daily scrum meeting.

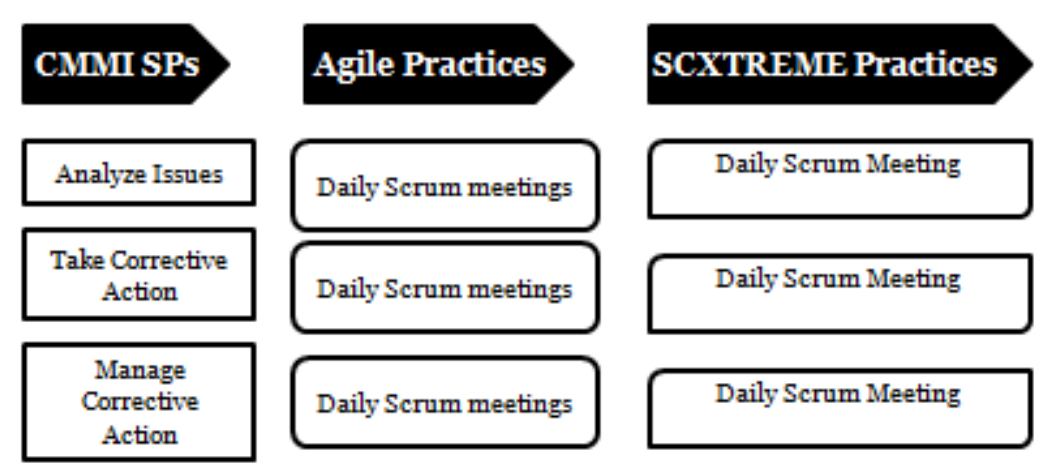

Fig. 20: Manage Corrective Action to Closure

\section{Conclusion}

The Proposed framework gives some mappings of agile with CMMI. Research work only identified some existing agile methods and map them CMMI process areas at level 2 and level 3. Agile is about to accept the change, but if the unlimited changes are accepted by organizations then agile become the cause of increase in budget and time and it may possible that project never fin ish at all. So management level (CMMI LEVEL 2) is important to implement in agile while performing agile development. 


\section{References}

[1] Muhammad Asim Ali. Survey on the state of Agile practices implementation in Pakistan. International journal of Information and Communication Technology Research (IJICTR). Volume 2, Issue No.5, May 2012

[2] Kishore R, Swinarski M, Jackson E, Raghav H. A Quality-Distinction Model of IT Capabilities: Conceptualization and Two-Stage Empirical Validation Using CMMI Processes[J]. Engineering Management, IEEE Transactions Journal, Volume PP Issue 99, October 2011.

[3] Zhang L, Shao D. Software Process Improvement for Small and Medium Organizations Based on CMMI. 2nd International Conference on Artificial Intelligence, Management Science and Electronic Commerce (AIMSEC), Aug 8-10, 2011

[4] Kovacheva T, Todorov N. Optimizing Software Development Process A case study for integrated Agile-CMMI process model. IEEE International Conference on Computer as a Tool (EUROCON), 2011

[5] Yi-Ling Kuo, Yu Nakamura, Chang-Shing Lee. Giving Awareness of Maturity by Capability Assessment. IEEE International Conference on Fuzzy Systems, June 27-30, 2011

[6] M. Nawazish Khokhar, Shafiq Ur Rehman, Arshad Mansoor, Muhammad Nadeem Khokhar, Abdul Rauf. MECA: Software Process Improvement for Small Organizations [C]. International Conference of Information and Emerging Technologies (ICIET), 2010

[7] Mahnic V. A Capstone Course on Agile Software Development Using Scrum[J]. IEEE Transactions on Education, Volume 55, Issue 1, February 2012.

[8] Deved V, Milenkovic R. Teaching Agile Software Development: A Case Study[J]. IEEE Transactions on Education, Volume 54, Issue 2, May 2011.

[9] Hisham M., Meredith D. A framework for instituting software metrics in small software organizations [J]. International Journal of Software Engineering, Volume 5, Issue 1, January 2012.

[10] Muhammad Ishfaq Khan, Muzaffar Ali Qureshi, Qaisar Abbas. Agile Methodology in Software Development (SMEs) of Pakistan Software Industry for Successful Software Projects (CMM Frame work)[C]. 201 O International Conference on Educational and Network Technology (ICENT 2010) Agile, 2010

[11] ZUXiao-Fang, ZHENG Jun-hon. Comparative Discussion on Free software and commercial software Development mode based on CMM theory. International Conference on Challenges in Environmental Science and Computer Engineering, 2010

[12] H.MALIK, H.O.SIEW. Review of Agile methodologies in software development. International Journal of Research and Reviews in Applied Sciences, Volume 1, Issue 1, October 2009.

[13] Rauf Abdul, Ramzan Muhammad, Anwar Sajid Shahid, Arshad Ali. Analysis of software process improvement efforts in Pakistan .The 2nd International Conference on Computer and Automation Engineering (ICCAE), 26-28 Feb. 2010.

Samina Jan: Engr. Samina Jan is a MS Scholar in Software Engineering Department, at University of Engineering and Technology Taxila, Pakistan. She graduated from International Islamic University Islamabad, Pakistan in Software Engineering in 2010. Her core areas of interest Requirement Engineering, Software Quality, Software Testing

Ali Javed: Engr. Ali Javed is serving as an Assistant Professor in the Department of Software Engineering, University of Engineering and Technology Taxila, Pakistan. He accomplished his M.Sc in Computer. engineering from university of Engineering and Technology Taxila, Pakistan in February, 2010. His areas of interest are Video Summarization, Digital Image Processing, Computer vision, Software Quality Assurance, Software testing and Software Requirements Analysis.

How to cite this paper: Samina Jan, Ali Javed,"SCXTREME Framework: A Customized Approach of Process Improvements in Agile Blend with CMMI Practices in Pakistan", International Journal of Information Technology and Computer Science(IJITCS), vol.5, no.3, pp.69-78, 2013.DOI: $10.5815 /$ ijitcs.2013.03.09 